\title{
Effect of land use/land cover changes on runoff in a river basin: a case study
}

\author{
J. Letha, B. Thulasidharan Nair \& B. Amruth Chand \\ College of Engineering, Trivandrum, Kerala, India
}

\begin{abstract}
A watershed is an area from which runoff resulting from precipitation flows past a single point into large streams, rivers, lakes, or oceans. Land use describes how a parcel of land is used whereas land cover refers to the materials that are prevailing on the surface. The change in land use type has considerable impact on the nature of runoff and related hydrological characteristics. In some area, land cover remains constant for long periods, revealing equilibrium between various human activities, natural hazards, and climate. In other areas, land cover undergoes progressive to drastic changes more frequently or over a larger expanse. Availability of remote sensing data from earth observation satellites has made it convenient to map and monitor land use/land cover at regional to local scales. The aim of this study is to analyse the discharge data of a river basin for a period of 40 years and to check whether there is any changes in the pattern of river flow due to the changes in the factors affecting runoff like land use/land cover during the study period The trend analysis of the runoff data shows that the peak discharge has an increasing trend over the period of time and low flow values have a decreasing trend. The rainfall runoff relationship derived for different periods revealed that the runoff generated from the same rainfall amounts showed an increasing trend towards the end of the study period. The land use land cover analysis showed that there is considerable increase in the built up area and barren lands at the expense of forest and other dense vegetations. Thus it is seen that the increasing pattern of peak flow and the decreasing pattern of low flow values are the result of land use/land cover change.
\end{abstract}

Keywords: land use, land cover, runoff, trend analysis, remote sensing, supervised classification, built up area. 


\section{Introduction}

A watershed is an area from which runoff resulting from precipitation flows past a single point into large streams, rivers, lakes or oceans. Land use describes how a parcel of land is used such as agriculture, settlements or industry, whereas land cover refers to the material such as vegetation, rocks or water bodies that are prevailing on the surface. It constitutes key environmental information for many scientific, resource management and policy purposes, as well as for a range of human activities. The change in land use type has considerable impact on the nature of runoff and related hydrological characteristics. In some area, land cover remains constant for long periods, revealing equilibrium between various human activities, natural hazards and climate. In other areas, land cover undergoes progressive to drastic changes more frequently or over a larger expanse. These changes usually relate to economic and social responses such as agricultural development, timber harvesting, or urbanization. It is well known that land cover changes influence watershed hydrology. Generally urbanization will increase peak discharge and runoff volume. It is needed to examine whether there is a change in discharge pattern in the rivers due to changes in land use land cover.

Infiltration and runoff are controlled by the nature of surface, material and land use pattern. Availability of remote sensing data from earth observation satellites has made it convenient to map and monitor land use/ land cover at regional to local scales. A land cover map is very critical for various planning activities including watershed planning.

Change in land use/land cover induced by urbanisation is important in understanding the change in runoff characteristics. Rajan and Ryosuke [1] have developed a GIS based integrated land use land cover change model to study Human-Land interactions. The changes are simulated annually and the entire process is carried out on a grid basis. A case study has been conducted from Zimbabwe by Jens et al. [2] assessing the effect of land use land cover change on the catchment runoff by combined use of statistical tests and hydrological modelling. Bhutiyani [3] analyzed the trend in stream flow patterns in the rivers of northwestern Himalayas as an implication of global warming in the $20^{\text {th }}$ century. The aim of this study is to analyse the discharge data of Vamanapuram River for a period of 40 years and to check whether there is any changes in the pattern of river flow due to the changes in the factors affecting runoff like land use/land cover during the period.

\section{Methodology}

The study involves the following:

1. Study of land use/land cover change in the basin.

2. Study of change of runoff characteristics in the basin.

3. Analyzing the changes in land use/land cover and runoff characteristics.

The changes in land use/land cover were studied using GIS and Remote sensing techniques. Survey of India Toposheets were used to study the land use/land cover pattern in 1967 and satellite images (IRS LISS III) were used to 
study the land use/land cover during the late 1990's, 2000, 2003 and 2007. Thus the changes that occurred during the past 40 years were quantified.

The runoff characteristics are studied using the runoff data at the outlet of the study area. About 40 years of data were used for the study. The annual maximum and annual minimum values are computed and their trend is analysed. The hydrographs at different periods are compared to study the change in pattern.

In order to smoothen short term variation in runoff, five year moving average for peak flow and low flow are also studied. A relationship between rainfall and runoff for various segments of the study period are also developed and the slope of the rainfall-runoff graph is analysed to assess the change in the runoff pattern. The change in land use/land cover pattern is obtained and possibility of correlating this change to the change in pattern of runoff is studied. The predominant factor causing the change in the runoff pattern is thus identified as the change in land use pattern. The study thus brings out the effect of land use/land cover changes on the discharge characteristics of a basin. The methodology for the study is given in Figure 1.

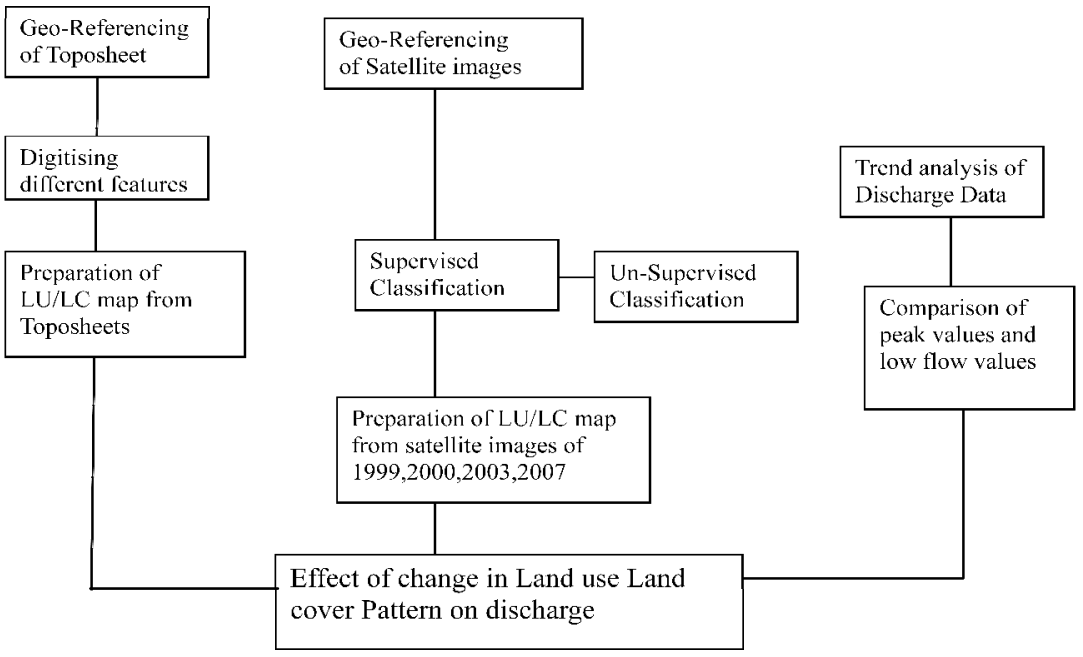

Figure 1: $\quad$ Flow chart of methodology.

\section{Study area and study materials}

The area selected for the study is the Vamanapuram River Basin which lies between $8^{\circ} 35^{\prime} \mathrm{N}$ to $8^{\circ} 50^{\prime} \mathrm{N}$ latitudes and $76^{\circ} 40^{\prime} \mathrm{E}$ to $77^{\circ} 15^{\prime} \mathrm{E}$ longitude and spreads over the districts of Thiruvananthapuram and Kollam of Kerala state, India. It is bounded by Kottarakara Taluk of Kollam district in the North, Nedumangaud Taluk of Thiruvananthapuram District in the South, Tamilnadu state in the East and Arabian Sea in the west. The watershed has a total area of $766.89 \mathrm{~km}^{2}$. The Major River is the Vamanapuram River, which has a length of about $88 \mathrm{~km}$. The shape of the water shed is almost elliptical with a length width ratio of $2: 1$. The 
watershed experiences an average rainfall of $2017 \mathrm{~mm}$ of which, $965 \mathrm{~mm}$ is received from southwest monsoon (June to August ) and $687 \mathrm{~mm}$ from Northeast monsoon (September to November). The location of the study area is shown in Figure 2. The gauging data for discharge, stage and cross-sectional data at Ayilam station of Vamanapuram River Basin are obtained from Central Water Commission, India for the period from 1978 to 2007.The satellite imagery (IRS 1C/1D LIS III images for the year 1999 and 2000 and IRS P6 Resource Sat images for the year 2003 and 2007) and toposheets (with numbers 58H1, 58H2, 58D13, and 58D 14 for the period-1967) are used for the study.

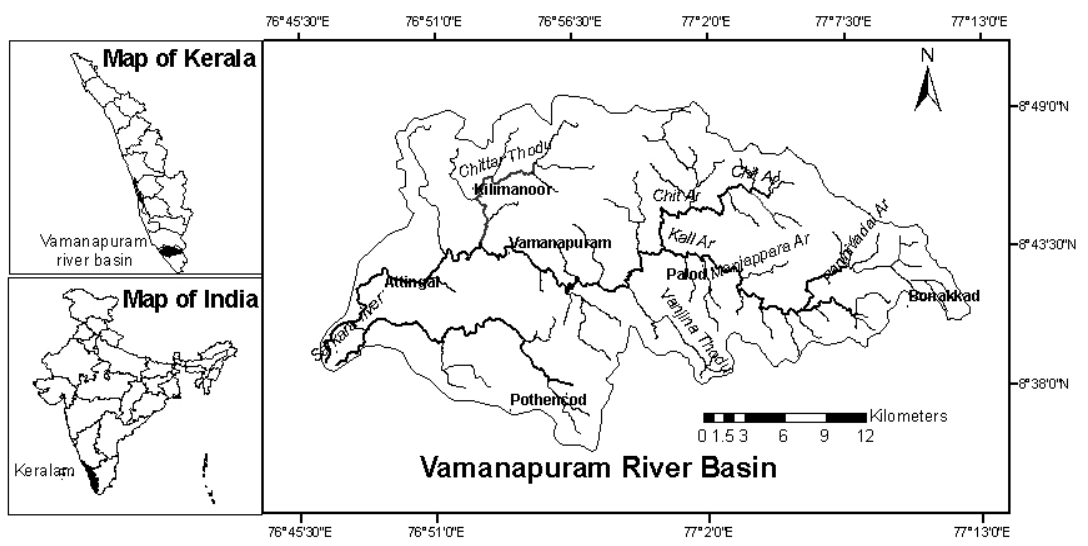

Figure 2: $\quad$ The study area.

The daily rainfall data from the year 1979 to 2007 for the stations Trivandrum, Nedumangadu, Varkala, Aryankavu, Kollam and Punalur are obtained from Indian Meteorological Department (IMD), Trivandrum. The daily rainfall data from the year 1979 to 2007 for the stations Attingal, Breamore, Vamanapuram, Ponmudi, Valayankil, and Mylamoodu stations are obtained from Hydrological Division, Irrigation Department, Thiruvananthapuram. Arc GIS9.1 and ERDAS IMAGINE 8.6 are the software used in the study.

\section{Rainfall-runoff analysis for the basin}

The daily discharge values of the basin for the period from 1979 to 2006 are obtained from the data collected at the gauging station Ayilam which is the outlet point of Vamanapuram basin. From these values annual peak discharge, annual minimum discharge, five years moving average for high flow and low flows are determined. For obtaining 5 years moving average hydrograph for peak flows and low flows, the average peak flows and the average low flows of five years were taken from the beginning.

To obtain relationship between rainfall and runoff for the basin rainfall data for the basin is required. Data from seven rain gauge stations are collected for 
Vamanapuram basin. The rain gauge stations are Attingal, Nedumangadu, Mylamoodu, Vamanapuram, Valayankil, Breamore and Ponmudi. The average rainfall is computed using Theisson polygon method.

\section{Preparation of land use/ land cover map}

The Toposheets covering the study area of Vamanapuram river basin are identified as 58H1, 58H2, 58D13, and 58D 14, all 1:50,000 maps. The various thematic maps such as drainage network, boundary of the basin, land use land cover classes etc. are derived from the toposheets using ArcGIS software. The co-ordinate system used is UTM Zone $43 \mathrm{~N}$ with WGS 84 as datum. Figure 3 shows the land use land cover classification for the study area derived from Toposheets for the year 1967. There are seven different land use/land cover classes found in the study area. They are water body, Hilly vegetation, Built up area with vegetation, Forest and other dense vegetation, Tea plantations, Eucalyptus plantation and Rubber plantations. It is difficult to get exact built up area from toposheets because the built up areas are surrounded by vegetations or open land everywhere and are found distributed over the entire area. Hence the built up area is divided into three categories: (i) built up area with $<10 \%$ vegetation (ii) Built up area with $10 \%$ to $50 \%$ vegetation (iii) Built up area with $>50 \%$ vegetation Thus the total area of built up with vegetation is calculated to be $297.49 \mathrm{~km}^{2}$. Table 1 gives the area under each land use/land cover classes in Vamanapuram basin derived from Toposheets for the year 1967 and these values are used as the base values for estimating the changes in the land use/land cover pattern.

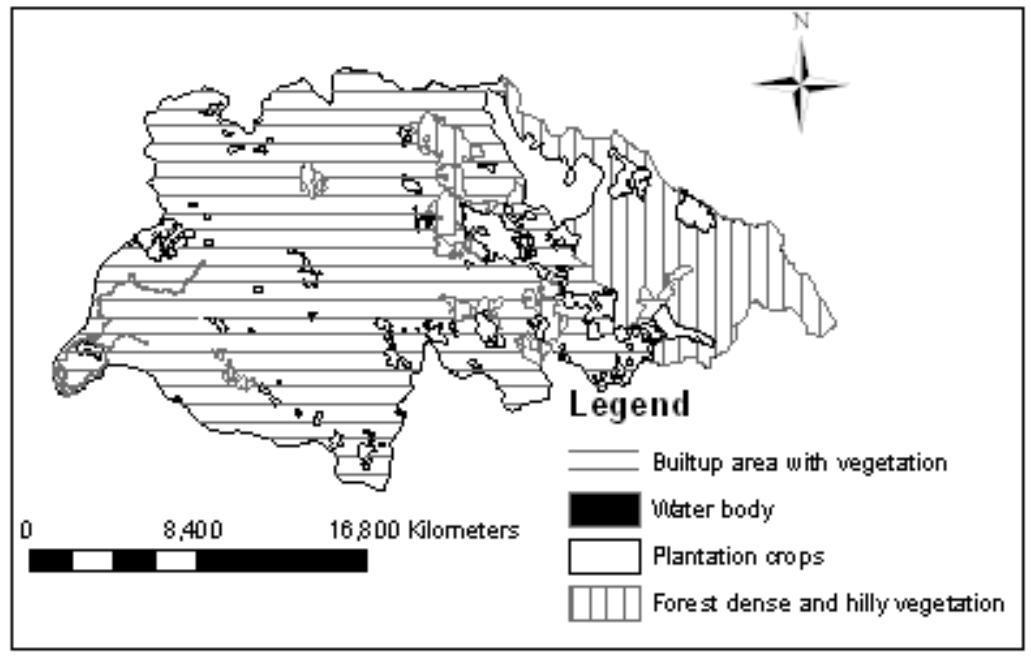

Figure 3: Land use land cover classification of Vamanapuram river basin using toposheet (1967). 
Table 1: $\quad$ Area under different land use/land cover derived from toposheet.

\begin{tabular}{|c|c|c|}
\hline Land Use & Area from & Total area \\
\hline Water body & 17.67 & 17.67 \\
\hline Hilly Vegetation & 30.19 & 30.19 \\
\hline \multicolumn{3}{|l|}{ Built up area with } \\
\hline$<10 \%$ vegetation & 200.78 & \multirow{3}{*}{297.49} \\
\hline $10 \%$ to $50 \%$ vegetation & 70.26 & \\
\hline$>50 \%$ vegetation & 26.45 & \\
\hline $\begin{array}{l}\text { Forest and other dense } \\
\text { vegetation }\end{array}$ & 290.15 & 290.15 \\
\hline Tea plantation & 25.51 & \multirow{3}{*}{61.65} \\
\hline Eucalyptus & 10.29 & \\
\hline Rubber plantation & 25.85 & \\
\hline
\end{tabular}

Land use land cover maps are also prepared from multispectral satellite images using image processing techniques in remote sensing. The software used is ERDAS IMAGINE 8.6. The images for the study area are extracted from the full scenes using the boundary map of Vamanapuram basin. Image processing techniques like contrast enhancement, band ratio, Non difference Vegetation Index (NDVI) etc. are done to identify different land use land cover classes. Field visits are also conducted to study present land use pattern with the help of a hand held GPS. The coordinate system used for the study is WGS 84, UTM zone $43 N$. The images used for the study are Indian Remote Sensing Satellite images (IRS LISS III 1C/1D and IRS P6 LISS III) for the years 1999, 2000, 2003, and 2007. The unsupervised classification is done on the satellite imageries of the year 1999, 2000, 2003 and 2007. The information obtained from techniques like NDVI, band ratio, unsupervised classification etc. are used as guides in supervised classification process. Signatures editors are created for all the four maps and supervised classification of all the four maps are done. Area of each class for the years 1999, 2000, 2003 and 2007 are obtained.

\section{Results and discussions}

\subsection{Trend analysis of runoff data}

The maximum, minimum and moving average values of runoff computed from the daily discharge values of Ayilam gauging station as already explained in section 3 are used for the trend analysis. Various plots using these values are made to perform the trend analysis. Figure 4 shows the variation of annual peak 
discharge over the time period. From the figure, it could be seen that the general tendency of peak discharges is to increase. The minimum flow in each year is selected and plotted against time and a trend line is fitted as shown in Figure 5. The trend line shows a decreasing trend. Also it can be seen from Figure 5 that the minimum flow never reached zero before 1982. But after 1995, in every year the summer flow attained zero level.

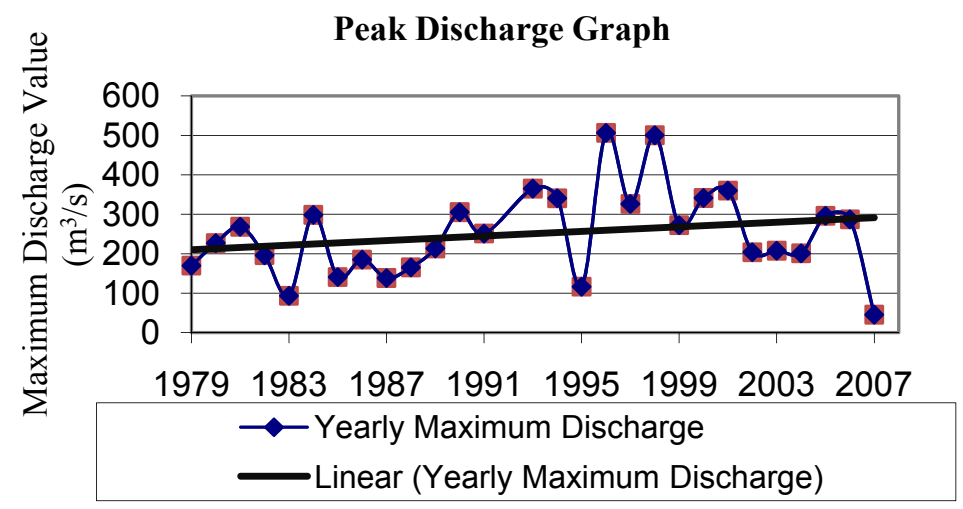

Figure 4: Variation of annual maximum discharge.

\section{Low flow values}

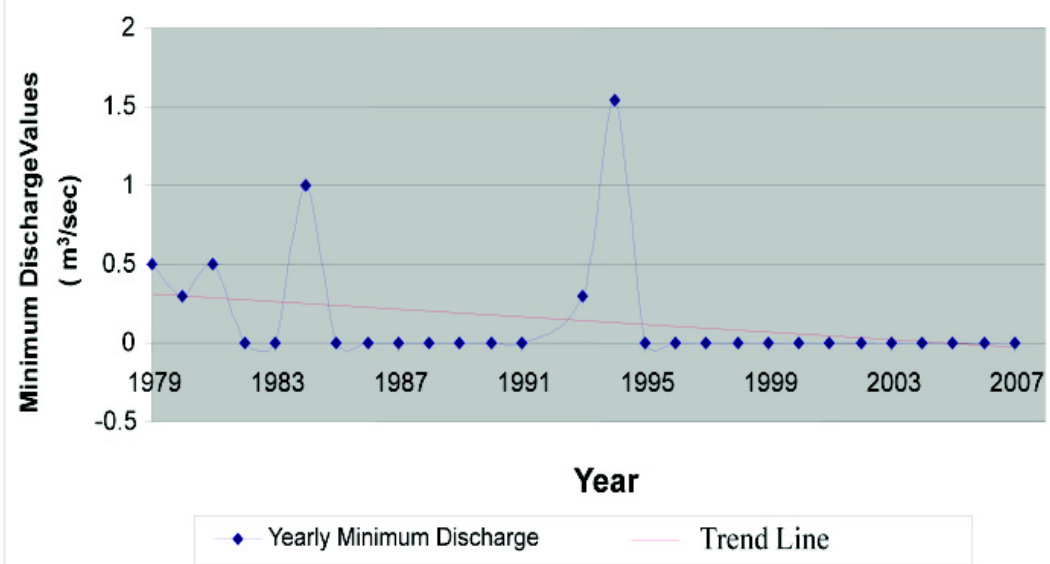

Figure 5: $\quad$ Variation of annual minimum discharge.

The moving peak discharge trend of the basin is also analysed. Figure 6 shows the five year moving average for high flow values. The trend is an increasing one. Figure 7 shows the five year moving average for low flow values. Before the year 1990, the number of times the low flow value recorded a 
lead to droughts. Thus the trend analysis of runoff data at Ayilam gauging station i.e. outlet of Vamanapuram river basin, it could be seen that the peak discharge shows a gradually increasing trend towards the end of the study period and the lean flow or summer flow shows a decreasing trend towards the end of study period.

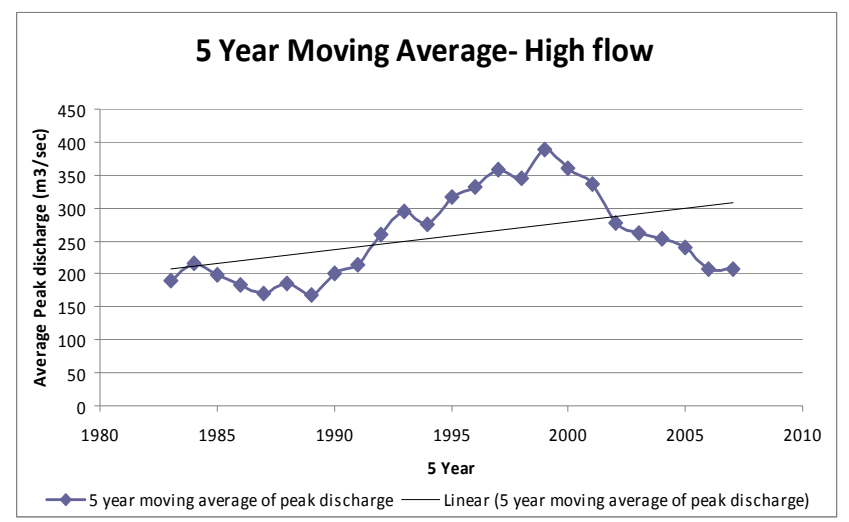

Figure 6: $\quad$ Five year moving average for peak flows.

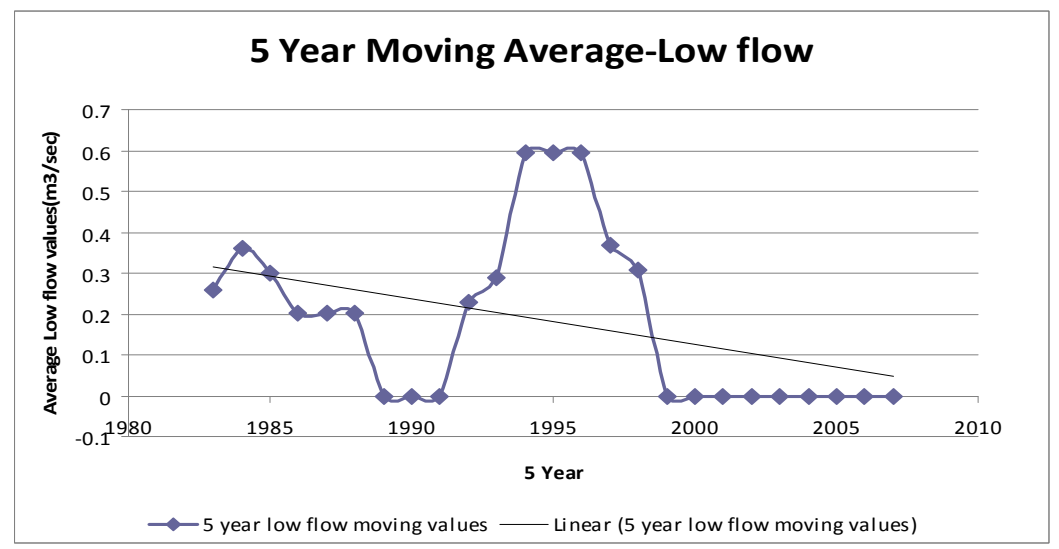

Figure 7: $\quad$ Five year moving average for low flows.

A general relation between rainfall and runoff is now estimated for different durations of the study period to know whether the increasing trend shown by the runoff is due to an increase in the rainfall trend or due to change in the water shed characteristics of the basin. From the whole study period three segments are selected for this analysis namely 1980-1984, 1990-1994 and 2000-2004. A linear regression analysis is made to get a relationship between rainfall and runoff during these periods i.e. 1980-1984, 1990-1994 and 2000-2004. Figure 8 shows the three trend lines and equations of the trend line. From the figure it could be 
seen that the slope of the curve gradually increases from one segment to the other i.e. from 1980-1984 to 1990-1994 and to 2000-2004. Thus for the same rainfall occurring during the three periods studied, the resulting runoff increases from 1980-84 to 2000-2004. Thus it can be inferred that the change in runoff pattern in the Vamanapuram River Basin is due to the change in the characteristics of the water shed. The study has to ascertain whether this change in runoff is due to the change in land use/land cover. Hence the change in land use pattern has to be quantified.

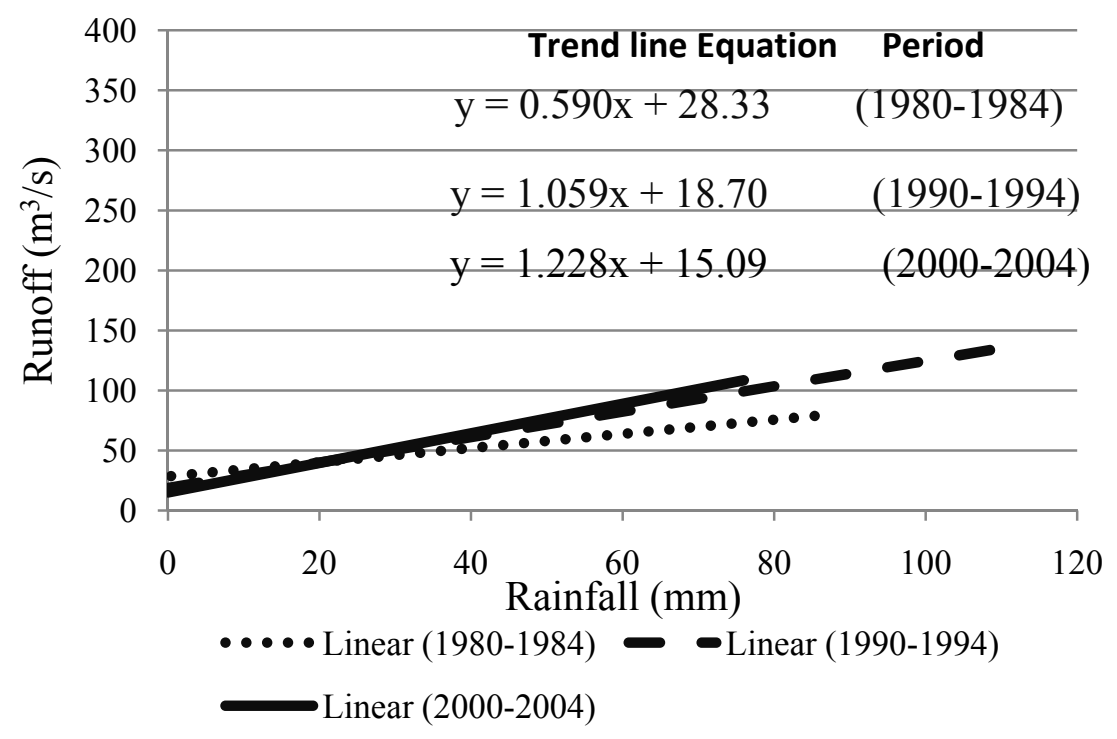

Figure 8: Rainfall-runoff relation for the periods 1980-1984, 1990-1994 and 2000-2004.

\subsection{Analysis of land use/land cover change}

The land use/land cover classification of the Vamanapuram River Basin for the year 1967 is done from toposheets and for the year 1999, 2000, 2003 and 2007 from satellite images. The built up area derived from toposheet was classified into three categories based on the amount of vegetation present along with the built up area as: built up with less than $10 \%$ vegetation, built up with less than $50 \%$ vegetation and built up with more than $50 \%$ vegetation. Thus the total built up area excluding vegetation was approximated to $75 \mathrm{~km}^{2}$. Table 2 shows the change in land use/land cover pattern of the basin for the years 1967, 1999, 2000, 2003 and 2007. From the table it can be seen that the built up area is increasing over the course of time while the hilly vegetation and forest area is decreasing. The built up area has increased from $75 \mathrm{~km}^{2}$ to $196.1 \mathrm{~km}^{2}$, i.e. a total increase of $261 \%$. At the same time, the forest area has decreased from $290.15 \mathrm{~km}^{2}$ to $93.78 \mathrm{~km}^{2}$, i.e. a total decrease of $67.67 \%$. A graph is plotted with the major land 
use classes and their change along with time to study the difference in land use/land cover pattern. Figure 9 shows the various land use/cover changes from the year 1967 to 2007. The cultivation areas of some crops have also varied in a large extent, but the decrease in cultivation area of one crop has been balanced by the increase in cultivation area of another crop.

Table 2: Change in land use/land cover pattern of Vamanapuram river basin.

\begin{tabular}{|c|c|c|c|c|c|}
\hline \multirow{2}{*}{$\begin{array}{c}\text { Land Use } \\
\text { Classification }\end{array}$} & 1967 & 1999 & 2000 & 2003 & 2007 \\
\hline & \multicolumn{5}{|c|}{ Area in $\mathbf{K m}^{2}$} \\
\hline Water & 17.67 & 17.21 & 17.19 & 12.7 & 12.73 \\
\hline $\begin{array}{c}\text { Hilly } \\
\text { Vegetation }\end{array}$ & 30.19 & 30.33 & 28.13 & 29.52 & 22.08 \\
\hline Built up & 75 & 120 & 125 & 160 & 196.10 \\
\hline $\begin{array}{l}\text { Forest and } \\
\text { dense } \\
\text { vegetation }\end{array}$ & 290.15 & 234.01 & 190.38 & 165.7 & 93.78 \\
\hline plantations & 61.65 & 80 & 82 & 85 & 87.02 \\
\hline
\end{tabular}

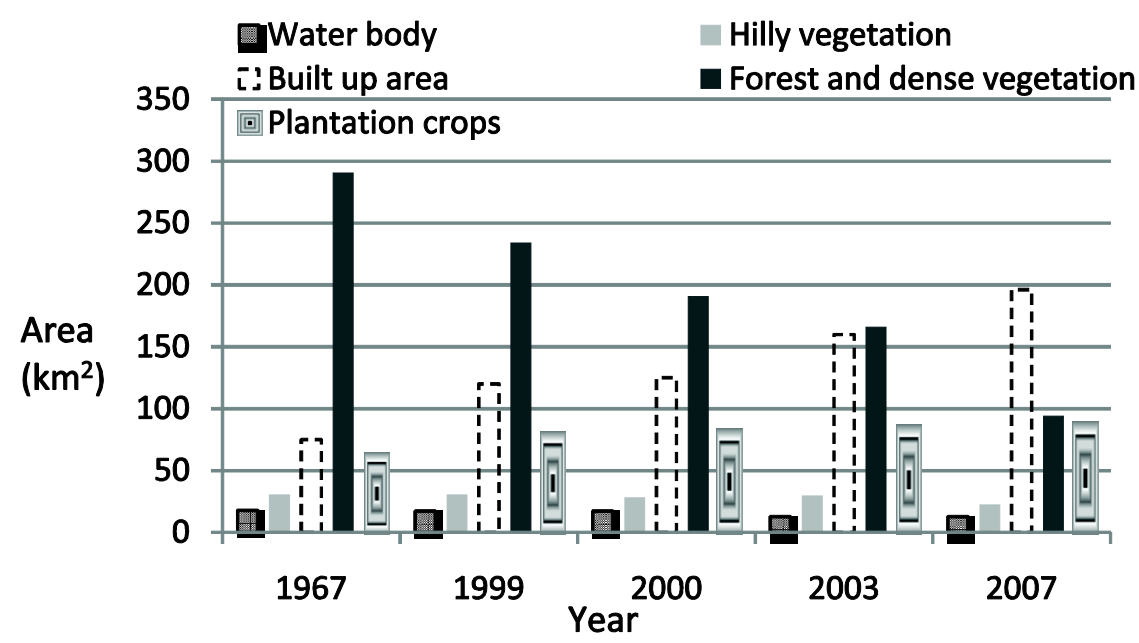

Figure 9: Various land use/land cover change from 1967 to 2007.

There is a progressive increase in the area of plantation crops mainly rubber. From the graph it can be seen that the increase in built up area has been very large compared to the rise in other land use classes. A similar decreasing trend is also observed in the forest area. The increase in built-up area along with decrease in forest area definitely leads to an increase in runoff in any basin. Hence it can 
be ascertained that in the study area selected the change in land use/land cover has a predominant effect on the runoff pattern.

\section{Conclusions}

From the study it can be concluded that as the land use/land cover pattern over a river basin changes, the runoff of the basin is also affected or changed. The built up area over any region generally increases over the course of time as the population increases which demand more and more availability of dwelling areas. The rise in built up area means there has to be a decrease in some other land use/land cover pattern and from this study it is seen that vegetated area is cleared for this purpose. The trend analysis of the runoff at Ayilam station of Vamanapuram River shows that the peak discharge has an increasing trend over the period of time and low flow values have a decreasing trend. The rainfall runoff relationship derived for different periods revealed that the runoff generated from the same rainfall amounts showed an increasing trend towards the end of the period. Thus it is concluded that the increasing pattern of peak flow and the decreasing pattern of low flow values are the result of land use/land cover change. Analysis of land use/land cover pattern shows that the built up area in the Vamanapuram River Basin is increasing at a very high rate, while the forest area has been constantly decreasing over the period of study. The built up area increased from $75 \mathrm{~km}^{2}$ to $196.10 \mathrm{~km}^{2}$, i.e. a total increase of $261 \%$. At the same time, the forest area has decreased from $290.15 \mathrm{~km}^{2}$ to $93.78 \mathrm{~km}^{2}$, i.e. a total decrease of $67.67 \%$. Hence water shed treatment activities should be started and control measures may be adopted for checking the conversion of land use.

\section{References}

[1] Rajan, K S and Ryosuke, S., A GIS based integrated Land use Landover model to study the Human-Land Interactions, International Archives of Photogrammetry and Remote Sensing, 2006

[2] Jens Kristian, L, Jens Kristian, R, and Dominic, M, Assessing the effect of land use change on catchment runoff by combined statistical tests and hydrological modelling. Journal of Hydrology, ASCE, Vol.205, pp. 147163., 1998

[3] Bhutiyani, M.R, Changing stream flow pattern in the rivers of northwestern Himalayas: Implication of global warming in the $20^{\text {th }}$ century. Research Article, Current Science, Vol.95, pp 618-626., 2006 